\title{
Dental Faculty's Knowledge and Attitude Regarding Covid 19 Disease in Qassim University, Saudi Arabia
}

\author{
Asma Munir Khan ${ }^{1}$, Shazia Nawabi ${ }^{2}$, Muhammad Qasim Javed ${ }^{3}$ \\ ${ }^{1}$ Assistant Professor, Department of Conservative Dental Sciences, College of Dentistry, Qassim University, \\ Al-Qassim, Saudi Arabia, ${ }^{2}$ Associate Professor, Department of Prosthetic Dental Sciences, College of Dentistry, \\ Qassim University, Al- Qassim, Saudi Arabia, ${ }^{3}$ Assistant Professor, Department of Conservative Dental Sciences, \\ College of Dentistry, Qassim University, Al-Qassim, Saudi Arabia.
}

\begin{abstract}
Background: Present study aimed to explore the knowledge and attitude of dental faculty at Qassim University, regarding novel COVID 19 disease.

Method: The cross-sectional survey was conducted on the faculty at undergraduate dental school. The selfdesigned e-survey was administered to 78 faculty members to assess their knowledge and attitudes towards the COVID-19 disease. Data analysis was conducted by using SPSS version 23. Descriptive statistics were reported as frequency and percentages. Chi-square test was utilized to identify the correlation between the independent and dependent variables. The inferential statistics (Kruskal-Wallis tests and Mann-Whitney U test) were utilized for assessing the significance between study variables. The association between knowledge and attitude was evaluated by using Spearman's rank correlation coefficient.
\end{abstract}

Results: A total of 55 faculty members (70.5\%) responded. Mean knowledge score was $10 \pm 2.71 .37$ (67.3\%) respondents showed positive attitude towards COVID-19 while 18(32.7\%) displayed negative attitude. The mean attitude score was $4.08 \pm 0.50$. Significant difference was found in knowledge ( $p$-value $=0.04)$ and attitude ( $\mathrm{p}$-value $=0.015$ ) of dental faculty based on designation.

Conclusions: Qassim University dentists were mindful of the COVID-19 symptoms, means of transmission, Cross-infection control and operative protocols practiced within dental clinics. However, dentists exhibited inadequate knowledge about the specific dental procedures that safeguard the dental staff and patients from COVID-19 in context of current outbreak.

Keywords: Knowledge, Attitude, COVID-19, cross-infection control, practice management.

\section{Introduction}

Human Coronaviruses have recently gained global attention after the emergence of a novel coronavirus that resulted in COVID 19 disease. ${ }^{1}$ COVID19 is a highly

\section{Corresponding Author:}

\section{Asma Munir Khan}

Assistant Professor, Department of Conservative Dental Sciences, College of Dentistry, Qassim University, AlQassim, Saudi Arabia

e-mail: asma.munir.k@gmail.com contagious viral infection that is caused by severe acute respiratory syndrome coronavirus 2 (SARS-CoV-2). ${ }^{2}$ It is composed of a single strand of RNA, $65-125 \mathrm{~nm}$ in diameter. SARS-CoV-2 has crown like spikes on its outer surface that binds to receptors of target cells and facilities its entry into the host cells. ${ }^{3}$ Additionally, its high binding affinity to the human angiotensin converting enzyme receptors (ACE2) enables it to enter and target the human host cells. ${ }^{4}$

The subgroups of coronaviruses family are alpha $(\alpha)$, beta $(\beta)$, gamma $(\gamma)$ and delta $(\delta)$ coronavirus [5]. Alpha and beta coronaviruses mainly cause disease 
in humans and mammals infecting their respiratory, gastrointestinal and central nervous system. ${ }^{5}$ SARS$\mathrm{CoV}-2$ is phylogenetically related to the two highly pathogenic respiratory coronaviruses i.e Severe acute respiratory syndrome coronavirus (SARS-CoV) and Middle East respiratory syndrome coronavirus (MERS $-\mathrm{CoV})$. All of these belong to $\beta-\mathrm{CoV}$ based on viral genoming ${ }^{6}$ and are profusely present in nasopharyngeal and salivary secretions of affected individuals. ${ }^{7}$ Initially, these viruses were believed to cause disease only in animals until the SARS-CoV triggered an outbreak in Guangdong, china in year 2002 resulting in severe acute respiratory syndrome (SARS) in humans. ${ }^{8}$ In 2012, another pathogenic coronavirus, known as Middle East respiratory syndrome coronaviruses (MERSCoV) caused an endemic in Middle Eastern countries. ${ }^{9}$

SARS-CoV-2 is a zoonotic pathogen that is believed to have been originated in bats and pangolins and later transmitted to humans. It can be transmitted from animal to human and then from human to human contact. ${ }^{6}$ This particular strain of coronavirus has recently originated from a seafood market in Wuhan city, China in late December 2019. The affected patients reported with a novel viral pneumonia with classical symptoms of fever, cough, myalgia, fatigue, with abnormal chest CT. The other symptoms reported were sputum production, headache, hemoptysis, diarrhea and respiratory distress. Later, it disseminated to other parts of world leading to global emergency. ${ }^{10}$

Novel coronavirus was officially announced as a causative agent of COVID -19 by the Chinese Centre for Disease Control and Prevention0. ${ }^{10}$ Owing to rapid dissemination World Health Organization (WHO) affirmed COVID-19 as a public health emergency of international concern (PHEIC). ${ }^{12}$ Subsequently, due to continue spread at an alarming rate WHO has formally declared outbreak a pandemic disease on 11th March 2020. Up till now (April 17th, 2020) it has swept more than 205 countries globally with 2,206,535 confirmed cases and 148,651 deaths. ${ }^{13}$

The current epidemiological data show COVID-19 has higher transmissibility than SARS-CoV and MERS$\mathrm{CoV}$. The possible routes of transmission in humans include direct contact through respiratory droplets inhalation and indirect through fomite transmission. ${ }^{7}$ Incubation period for COVID-19 is between 2 to 14 days and it can also be transmitted through asymptomatic patients. ${ }^{14}$ Thus, social distancing, proper hand hygiene, and surface disinfection are highly recommended to stop its rapid spread. Moreover, it was also found in saliva of infected patients. This can be attributed to its high binding capacity to ACE2 receptors which are highly concentrated in salivary glands. ${ }^{4}$ Thus, its high mutation rate, pathogenicity and numerous routes of transmission may contribute to nosocomial spread in healthcare settings especially dental offices. Up till now, no treatment or vaccine is available to treat COVID-19 disease and the main stay of the treatment is supportive care. The only critical intervention, available is preventive measures as advised by WHO is early viral testing for disease confirmation and ensuring symptomatic relief for infected patients. ${ }^{13}$

Dental professionals and patients are at an increased risk of contracting COVID -19 due to specific nature of dental procedures which involves frequent face to face contact with the patients, their saliva and contaminated materials. Owing to rapid spread and poor understanding of the disease, the American Dental Association has suggested that all elective dental procedures should be deferred and only patients with true dental emergencies should be catered. ${ }^{15}$ Also, universal precautions, careful prescreening of patients and additional preventive measures are deemed necessary before treating the patients in dental settings. ${ }^{13}$

It is mandatory for health professionals to provide good and safe patient care. Therefore, it is imperative that proper information and training sessions should be imparted to dental professionals to ensure awareness and readiness regarding this global emergency.Absence of proper training will not only delay the necessary treatment required for such patients but can contribute to rapid spread of disease. Hence, the present study aimed to explore the knowledge, and attitude of dental faculty at Qassim University, regarding novel COVID-19 disease. This survey intended to provide an insight regarding level of awareness among dentists about the Covid-19 disease and may help in shaping future guidelines, strategies, and fool proof infection control policies that wil be implemented in dental settings.

\section{Method}

Study Design, Participants and Site: The current cross-sectional study was conducted on the Faculty at Qassim University College of Dentistry from $15^{\text {th }}$ to $31^{\text {st }}$ March, 2020. All the faculty members were briefed about the context and purpose of the research. An 
online e-survey questionnaire was administered through an electronic mail to 78 faculty members to assess their knowledge and attitudes towards the COVID-19 disease. The study instrument was devised by a panel of experts according to the guidelines proposed by WHO and CDC. ${ }^{13,16,17}$ The instrument was then sent to the researchers from dental background to provide expert opinion on the ease of understanding, relevancy and time needed to fill. A second review was done and the modification in the questionnaire was carried out according to local requirements. Subsequently, a pilot study was carried out on limited sample of dental professionals $(\mathrm{N}=6)$. The professionals provided suggestions on making the study instrument shorter and simpler. After a comprehensive discussion, the study instrument was finalized. The instrument was found to be reliable with the Cronbach's alpha of 0.77 . The study instrument was divided into 3 parts. The first section of the e-survey constituted demographic questions inquiring about gender, designation and specialty. The second section included 13 research questions pertaining to participants' knowledge regarding COVID-19 disease where yes and no options were provided for each question. The third part of the survey used 9 questions to ascertain the attitude of the faculty members towards COVID-19 disease on a 5-point Likert scale that was developed with balanced responses and neutral midpoint.

The study tool assessed the awareness of faculty by probing about the mode of transmission, prevention, treatment and management of patients in the dental settings. The score for knowledge assessment ranged from 0 to13. The cutoff point of less than $9(<9)$ was set for insufficient knowledge and greater than or equal to 9 ( $\geq 9)$ for sufficient knowledge. Attitude assessment was conducted, and the responses were documented on 5 point Likert scale. A score of 5 was assigned to strongly agree, 4 to agree, 3 to undecided, 2 to disagree and 1 to strongly disagree. A mean score of $>4$ was taken as positive attitude whereas score of $<4$ was considered as negative attitude.

Ethics, consent and permissions: The study was approved by the ethical committee of the Qassim University College of dentistry (Ref no ST/6074/2020). Furthermore, written consent was not obtained as the returning of filled questionnaires from respondents was taken as implied consent. Moreover, participants were informed about intent and content of study and were ensured about confidentiality of data
Statistical Analysis: Data analysis was done by using SPSS version 23 (IBM Corp, 32 Armonk, N.Y., USA). Descriptive statistics were described in terms of frequency and percentages. In order to show association between dependent and independent variables Chi -square test was employed. Statistical significance was set at less than 0.05 ( $p$-value $<0.05)$. Also, the inferential statistics (Kruskal Wallis tests and Mann-Whitney U test, $\mathrm{p}<0.05$ ) were utilized for assessing the significance between study variables. The aforementioned nonparametric tests (Kruskal Wallis tests and MannWhitney U test) were applied because of smaller sample size. Spearman's rank correlational coefficient was used to appraise any link between knowledge and attitude. $(\mathrm{p}<0.05)$.

\section{Results}

A total of 55 faculty members, 31 females and 24 males, responded out of 78 . About $74 \%$ of the participants belonged to clinical specialties and majority of the respondents were Lecturers (38.2\%). The distribution of respondents' characteristics is shown in Table 1.

Overall the mean knowledge score of the participants was $10 \pm 2.71$. Sufficient knowledge was exhibited by $72.7 \%$ of respondents whereas $27.3 \%$ displayed insufficient knowledge. The study participants showed excellent knowledge (between 98\% to $80 \%$ ) for the stems that enquired about mode of transmission, urgent dental care procedures, significance of PPE while patient examination, use of high volume suction and WHO guidelines regarding hand hygiene. On the other hand, knowledge was good to fair (between $80 \%$ to $70 \%$ ) for questions regarding rubber dam isolation, use of N95 masks, four handed dentistry, extraction protocol, antibiotic use and tele screening. Lastly, inadequate knowledge was evident in reaction to two questions, one regarding safety of use of ultrasonic in Covid-19 suspected patients and the other was related to efficacy of $1 \%$ of hydrogen peroxide mouthwash as a pre-rinse. Response was $61.2 \%$ and $38.2 \%$ respectively. Table 2 describes knowledge of participants regarding COVID19 disease in detail.

Attitude of the respondents is summarized in Table 3. Of 55 respondents, $37(67.3 \%)$ showed positive attitude $(>4)$ towards COVID-19 while 18 respondents $(32.7 \%)$ displayed negative attitude $(<4)$ regarding disease. The mean attitude score was in range of $4.08 \pm 0.50$. Overall faculty showed positive attitude 
when asked about fear of getting infected with COVID 19, treating only emergency cases, seeking patient's relevant medical history, asking about recent travel, checking body temperature and avoiding procedures that cause aerosol production. Conversely, the most negative attitude $(3.42 \pm 1.08)$ was noted when the faculty was asked if they would like to volunteer their services in support of medical teams in case of future emergencies. Moreover, mean scores were found to be $<4$ in questions related to anxiety, caries removal and training sessions. Significant correlation was noted between designation and attitude for items number $6(p$-value $=0.001)$ and 7 (p-value $=0.03$ ).

In table 4, the relationship of demographic characteristics with mean attitude and knowledge amongst dental faculty is displayed. Results of the present study showed no significant correlation of gender and specialty with both knowledge and attitude. However, a meaningful disagreement was found in knowledge and attitude of dental faculty on the basis of designation. The results showed that Professors/associate professors were equipped with better knowledge and attitude regarding COVID-19 disease than lecturers. Spearman correlation showed significant positive correlation between the knowledge level and attitude of faculty members about COVID-19 $(\mathrm{r}=0.557, \mathrm{p}$ value $=0.01)$.

Table 1: Distribution of faculty members according to their characteristics

\begin{tabular}{|l|c|}
\hline Descriptions & Faculty Members N (\%) \\
\hline Gender & $31(56.4)$ \\
\hline Female & $24(43.6)$ \\
\hline Male & \multicolumn{2}{|l}{} \\
\hline Designation & $17(30.9)$ \\
\hline Associate Prof/Professor & $17(30.9)$ \\
\hline Assistant Professor & $21(38.2)$ \\
\hline Lecturer & \\
\hline Specialty & $14(25.5)$ \\
\hline Preclinical & $41(74.5)$ \\
\hline Clinical &
\end{tabular}

Table 2: Knowledge of Faculty members about COVID 19

\begin{tabular}{|c|c|c|}
\hline Knowledge of COVID19 & $\begin{array}{c}\text { Correct } \\
\text { Answer N (\%) }\end{array}$ & $\begin{array}{c}\text { Incorrect } \\
\text { Answer N (\%) }\end{array}$ \\
\hline Mode of transmission of COVID 19 is Fomite transmission and by respiratory droplets. & $54(98.2)$ & $1(1.8)$ \\
\hline $\begin{array}{l}\text { WHO suggests that washing hands with water and soap for minimum } 20 \text { secs can help in the } \\
\text { prevention of disease transmission }\end{array}$ & $45(81.8)$ & $10(18.2)$ \\
\hline $\begin{array}{l}\text { Tele- screening via phone is recommended as first line of action to identify patients with } \\
\text { possible COVID } 19\end{array}$ & $39(70.9)$ & $16(29.1)$ \\
\hline $\begin{array}{l}\text { Urgent dental care includes severe toothache, cellulitis, Ludwig's angina, uncontrolled bleeding } \\
\text { and Oro-facial trauma }\end{array}$ & $53(96.4)$ & $2(3.6)$ \\
\hline $\begin{array}{l}\text { Most effective mouth wash as a pre- rinse to protect against COVID } 19 \text { infection is } 1 \% \\
\text { hydrogen peroxide }\end{array}$ & $21(38.2)$ & $34(61.2)$ \\
\hline Four handed dentistry is highly recommended for controlling the spread of disease & $42(76.4)$ & $13(23.6)$ \\
\hline Face shields and eye wear are essential while examining the patients & $50(90.9)$ & $5(9.1)$ \\
\hline Ultrasonic devices can be safely used in dental office for patients & $34(61.2)$ & $21(38.2)$ \\
\hline After extraction resorbable sutures should be used in patients & $41(74.5)$ & $14(25.5)$ \\
\hline $\mathrm{N}-95$ mask is essential while examining the patients & $42(76.4)$ & $13(23.6)$ \\
\hline Rubber dam isolation is a prerequisite for every patient & $43(78.2)$ & $12(21.8)$ \\
\hline High volume suction is mandatory in dental practice & $44(80)$ & $11(20)$ \\
\hline Antibiotics are the first line of treatment & $41(74.5)$ & $14(25.5)$ \\
\hline
\end{tabular}

Note: Assessment of knowledge was done by awarding 0 for incorrect answer and 1 for correct answer. The range of knowledge score was from 0 to 13. Cumulative score of less than 9 was considered as insufficient score whereas greater than 9 were considered as sufficient knowledge score. Mean value of knowledge score $=10 \pm 2.71$. 
Table 3: Attitude of Faculty Members towards COVID 19

\begin{tabular}{|c|c|c|c|c|c|c|c|c|}
\hline \multirow{2}{*}{ Items } & \multicolumn{5}{|c|}{ Faculty's Responses" N (\%) } & \multicolumn{3}{|c|}{ p-value } \\
\hline & SA & $\mathbf{A}$ & $\mathbf{U}$ & D & SD & Gender $^{2}$ & Designation $^{3}$ & Specialty $^{2}$ \\
\hline $\begin{array}{l}1 \text { Are you scared of getting infected with Covid -19 } \\
\text { from a patient or a co -worker? }\end{array}$ & $19(34.5)$ & $24(43.6)$ & $7(12.7)$ & $4(7.3)$ & $1(1.8)$ & 0.78 & 0.74 & 0.44 \\
\hline $\begin{array}{l}2 \text { Are you anxious of providing treatment to a } \\
\text { patient who is suspected of being infected with } \\
\text { Covid } 19 ?^{\text {b }}\end{array}$ & $11(20 \%)$ & $26(47.3)$ & $8(14.5)$ & $6(10.9)$ & $4(7.3)$ & 0.93 & 0.62 & 0.16 \\
\hline $\begin{array}{l}3 \text { Currently every patient's travel history and body } \\
\text { temperature should be taken before performing } \\
\text { any dental procedure }\end{array}$ & $36(65.4)$ & $16(29.1)$ & $2(3.6)$ & $0(0)$ & $1(1.8)$ & 0.27 & 0.46 & 0.48 \\
\hline $\begin{array}{l}4 \text { Relevant medical history i.e respiratory illness } \\
\text { like cough, sputum, fever, difficulty in breathing } \\
\text { should be sought for every patient }{ }^{\mathrm{d}}\end{array}$ & $40(72.7)$ & $13(23.6)$ & $0(0)$ & $0(0)$ & $2(3.6)$ & 0.35 & 0.09 & 0.60 \\
\hline $\begin{array}{l}5 \text { Only emergency dental procedures should be } \\
\text { carried out in current circumstances }\end{array}$ & $45(81.8)$ & $8(14.5)$ & $0(0)$ & $0(0)$ & $2(3.6)$ & 0.25 & 0.77 & 0.47 \\
\hline $\begin{array}{l}6 \text { Aerosol generating procedure such as use of triple } \\
\text { syringe should be minimized as much as possible }\end{array}$ & $33(60)$ & $12(21.8)$ & $9(16.4)$ & $0(0)$ & $1(1.8)$ & 0.10 & $0.001^{1}$ & 0.12 \\
\hline $\begin{array}{l}7 \text { Chemo mechanical method should be used } \\
\text { for caries removal in patients with Irreversible } \\
\text { pulpitis }^{\mathrm{g}}\end{array}$ & $10(18.2)$ & $19(34.5)$ & $19(34.5)$ & $5(9.1)$ & $2(3.6)$ & 0.16 & $0.03^{1}$ & 0.82 \\
\hline $\begin{array}{l}8 \text { Would you like to attend any training sessions to } \\
\text { handle any untoward Covid } 19 \text { situation? }\end{array}$ & 17(30.9) & $22(40)$ & $11(20)$ & $3(5.4)$ & $2(3.6)$ & 0.67 & 0.45 & 0.78 \\
\hline $\begin{array}{l}9 \text { Would you like to volunteer for working in } \\
\text { support of medical teams in case of emergency? }\end{array}$ & $11(20)$ & $13(23.6)$ & $21(38.2)$ & $8(14.5)$ & $2(3.6)$ & 0.38 & 0.43 & 0.93 \\
\hline
\end{tabular}

Posthoc $^{1}$ Tukey

Derived from ${ }^{2}$ Chi-square test and ${ }^{3}$ Kruskal Wallis test

*Strongly disagree $=\mathrm{SD}$; Disagree $=\mathrm{D}$; Undecided $=\mathrm{U}$; Agree $=\mathrm{A}$; Strongly agree $=\mathrm{SA}$

Note: Mean attitude score $=4.08+0.50$

Mean Attitude value \pm Standard deviation: $\mathrm{a} 4.02 \pm 0.97, \mathrm{~b} 3.62 \pm 1.14, \mathrm{c} 4.56 \pm 0.74, \mathrm{~d} 4.62 \pm 0.83, \mathrm{e} 4.71 \pm 0.81, \mathrm{f} 4.38 \pm 0.90, \mathrm{~g} 3.55 \pm$ $1.02, \mathrm{~h} 3.89+1.03, \mathrm{i} 3.42+1.08$

Table 4: Mean score of Knowledge and Attitude.

\begin{tabular}{|c|c|c|c|c|c|c|c|}
\hline Description & $\mathbf{N}(\%)$ & $\begin{array}{l}\text { Knowledge } \\
\text { score (Mean } \\
\quad \pm \text { SD) }\end{array}$ & $\begin{array}{l}\text { Mean } \\
\text { Rank }\end{array}$ & p-value & $\begin{array}{c}\text { Attitude score } \\
(\text { Mean } \pm \text { SD) }\end{array}$ & Mean Rank & p-value \\
\hline \multicolumn{8}{|l|}{ Gender** } \\
\hline Male & $24(43.6)$ & $10.42 \pm 2.2$ & 29.60 & \multirow{2}{*}{0.51} & $4.12 \pm 0.40$ & 28.06 & \multirow{2}{*}{0.98} \\
\hline Female & $31(56.4)$ & $9.68+3.04$ & 26.76 & & $4.05 \pm 0.63$ & 27.95 & \\
\hline \multicolumn{8}{|l|}{ Designation* } \\
\hline Associate Prof/Professor & $17(30.9)$ & $11 \pm 2.06$ & 34.21 & \multirow{3}{*}{0.04} & $4.18 \pm 0.38$ & 30.53 & \multirow{3}{*}{0.015} \\
\hline Assistant Professor & $17(30.9)$ & $10.10 \pm 2.83$ & 28.81 & & $4.18 \pm 0.65$ & 33.33 & \\
\hline Lecturer & $21(38.2)$ & $8.88 \pm 2.85$ & 20.79 & & $3.85 \pm 0.46$ & 18.88 & \\
\hline \multicolumn{8}{|l|}{ Specialty $^{* *}$} \\
\hline Preclinical & $14(25.5)$ & $9.86 \pm 3.18$ & 28.91 & \multirow{2}{*}{0.95} & $3.99 \pm 0.66$ & 27.36 & \multirow{2}{*}{0.86} \\
\hline Clinical & $41(74.5)$ & $10.05 \pm 2.56$ & 27.93 & & $4.11 \pm 0.50$ & 28.22 & \\
\hline
\end{tabular}

*Kruskal Wallis Test $(\mathrm{p}<0.05)$. **Mann Whitney Test $(\mathrm{p}<0.05)$. 


\section{Discussion}

Pandemic of COVID-19 has led to global crisis. The rapid surge of COVID-19 disease has not only raised widespread public health concerns but has collapsed world's economy. It has put immense strain on social stability and the global health systems, particularly challenging the health care workers including the Dental care professionals (DCP). It is, therefore, crucial that prudent information should be relayed to health care professionals in the time of this global emergency. Considering this, the current study investigated the knowledge and attitude of dental faculty towards the COVID-19 disease. To date, only limited studies are reported that explored dentist' awareness and attitude towards COVID-19 contagion. Due to scare data available, the comparison of our outcomes has been done mainly with other associated conditions.

The current study revealed generally adequate knowledge and positive attitude of Qassim University dental faculty towards the COVID-19 disease. Most of the participants exhibited sufficient knowledge about questions related to mode of disease transmission, urgent dental care procedures, significance of PPE while examination, use of high volume suction and WHO guidelines regarding hand hygiene. These outcomes are in accordance with the results reported by Khader et al. in their study on the Jordanian dentists. ${ }^{18}$ Moreover, the findings are consistent with outcomes of other studies in which Health care workers showed positive attitude and adequate implementation of personal protective equipment and hand disinfection protocol whiling dealing with SARS-CoV and MERSCoV. ${ }^{19,}$ 20, 21 These outcomes are promising as good hygiene practices and disinfection can cause decrease in morbidity and death rate. This level of awareness can be attributed to the comprehensive awareness campaigns run by International and National health authorities. We are living in a world where the social media has revolutionized communications. Social networks have become the central facilitator for daily transmission by emerging as a powerful communication medium. ${ }^{22}$ However, the DCP's should be well informed about the unverified harmful information that can disseminate quickly and can result in the misguidance. Considering this, the scientists and health authorities have cautioned the DCPs should carefully assess the information related to COVID-19 and should utilize only the authentic and scientific literature as a source of information. ${ }^{23,24}$
On the other hand, with regard to the questions related to rubber dam isolation, four handed dentistry. ${ }^{25}$, ${ }^{26}$ Use of N95 mask, role of antibiotics, tele-screening and recommended extraction protocol and faculty exhibited moderate knowledge. Possible explanation for these findings could be the knowledge gap and poor understanding of disease transmission via high aerosol production during dental procedures. These results are comparable to some of the studies which concluded that dentists' knowledge of respiratory disease contagion and its management was less as compared to other healthcare providers. ${ }^{27}$ Despite their proximity to the patient during treatment. ${ }^{28}$ Likewise, in a study conducted in Qassim in perspective of MERS, majority of health workers $(57.6 \%)$ replied incorrectly when asked whether antibiotics are first choice drugs. ${ }^{21}$ This outcome is comparable with the result of another study where $40 \%$ of participants gave negative response when asked about specialized management protocols. ${ }^{29}$ This might be due to the inadequate briefing of the relevant authorities on the management issues during the educational campaign. Moreover, moderate knowledge about the aforementioned questions in our study might be due to the fact that in Saudi Arabia after the outbreak of COVID-19 more seminars are held for medical healthcare workers as compared to dentist community. Inadequate knowledge was ostensible in reply to two questions, one regarding safety of use of ultrasonic in Covid-19 suspected patients and the other was related to efficacy of $1 \%$ of hydrogen peroxide mouthwash as a pre-rinse.

Moreover, further insight into the study showed a positive mean value in attitude domain. These results are consistent with other studies which showed mean positive attitude of physicians. ${ }^{30,31}$ Dental faculty showed most affirmative response and positive attitude in reply to questions about anxiousness regarding cross infectivity, to accommodate only emergency cases, seeking patient's relevant medical and travel history and minimization of aerosol generating procedures. The anxiety of our faculty regarding cross infectivity are contradictory to results of recent study, where most of the dentists $(71.7 \%)$ perceived COVID-19 as moderately dangerous disease and almost one third believed that COVID-19 is not a serious public health issue. Although same study concluded that dentists should evaluate patients through measurement of the body temperature as a routine procedure and should be asked about any history of recent contact or travel [18], 
and these results are in accordance with our study. These findings are also in harmony with another study in which health care workers displayed positive attitude in using personal protective gear and were adamant that goggles and gloves should be worn when dealing with healthcare related nosocomial infections. ${ }^{32}$

The most negative attitude was seen in question no $9(3.42 \pm 1.08)$ in which faculty was asked if they would like to volunteer their services in support of medical teams in case of future emergency. So far, there is no comparable data to assess the attitude of dentists about their involvement in COVID-19 emergency support teams but there is one recent study, which has presented model of dental outreach program in case of any untoward emergency situation in current diseases outbreak. ${ }^{33}$

In present study mean scores were also found to be negative (less than 4) in question no 7 and 8 , regarding willingness of dental faculty to attend any training sessions to handle any untoward Covid 19 situation. The reason for this negative response may be wrong perception of faculty, to link these training sessions as part of building volunteer teams. It was noticed that experience was appreciably linked with attitude, as senior faculty responded more positively as compared to younger ones, and this finding is comparable to study done during MERS outbreak in Middle East. ${ }^{21}$

The relationship of demographic data with mean awareness and attitude was analyzed and results showed no significant correlation among the demographic variables, gender and specialty. These results are supported by literature which does not support the connection of gender with the awareness and attitude of healthcare workers. ${ }^{34}$ Although, the correlation of experience with awareness and attitude, has been stated meaningful by studies. ${ }^{35}$ Our study also exhibited a significant disparity in knowledge ( $p$-value $=0.04)$ and attitude $(p$-value $=0.015)$ of dental faculty with respect to their designation. Professors/Associate professors were equipped with better knowledge and attitude regarding COVID19 disease than lecturers. This can be attributed to vision and experience of senior faculty members earned through years than the lecturers who are relatively young and new to the field.

The aforementioned findings, endorses meaningful association of awareness and attitude of dental faculty with regard to COVID -19. In light of this, it could be inferred that dentists depicting positive attitude are highly determined to gain information and to enhance their knowledge and skills to fight against disease. This can be rationalized by the philosophy of Reasoned Action, which states that an individual's intent to a particular action depends on their attitude towards that conduct. ${ }^{36}$ Nevertheless, more extensive studies in future should be undertaken to explain possible correlation between knowledge and attitude displayed by dental faculty at Qassim. The merits of this study lie in its concept of addressing current pandemic dilemma and highlighting the area where little research has been done until now.

The key results of present study may be used to create awareness in designing efficient infection control measures of COVID-19. However, our study has certain limitations, the lower than expected response rate of faculty and short period of data collection has led to comparatively smaller sample size. Moreover, this pandemic has affected every aspect of life and caused many to be busy in making personal, official, and financial arrangements. This could have been resulted in selection bias and sampling error, which may limit the ability to generalize our results. Future studies are required in this context.

\section{Conclusions}

In summary, Qassim University dentists were mindful of the COVID-19 symptoms, means of transmission, Cross-infection control and operative protocols practiced within dental clinics. However, dentists exhibited inadequate knowledge about the specific dental procedures that safeguard the dental staff and patients from COVID-19 in context of current outbreak. Study recommends establishment of focused dental education drives to span the gap between the current and the requisite knowledge, to influence their attitude positively towards COVID-19.

\section{Abbreviations: Not applicable}

Acknowledgements: We wish to thank the faculty members who participated in the study.

\section{Authors' Contributions:}

AMK and SN designed the study, MQJ and AMK collected the data, MQJ conducted data analysis, all authors contributed to writing. The authors read and approved the final manuscript.

Funding: Not Applicable 
Availability of data and materials: The datasets generated and/or analysed during the current study are not publicly available due to ethics approval but are available from the corresponding author on reasonable request.

Ethics approval and consent to participate: Ethics approval was provided by the institutional ethical review committee of Qassim University.

Consent for Publication: Not applicable.

Competing Interests: The authors declare that they have no competing interests.

\section{References}

1. Lee TL. Global Health in a Turbulence Time: A Commentary. Asian Journal of WTO \& International Health Law and Policy. 2020;15:2760 .

2. Zhong N, Zheng B, Li Y, Poon L, Xie Z, Chan $\mathrm{K}$, et al. Epidemiology and cause of severe acute respiratory syndrome (SARS) in Guangdong, People's Republic of China, in February, 2003. The Lancet. 2003;362:1353-8.

3. Fehr AR, Perlman S. Coronaviruses: an overview of their replication and pathogenesis. InCoronaviruses 2015 (pp. 1-23). Humana Press, New York, NY.

4. Wan Y, Shang J, Graham R, Baric RS, Li F. Receptor recognition by the novel coronavirus from Wuhan: an analysis based on decade-long structural studies of SARS coronavirus. Journal of virology. 2020;94. https://doi.org/10.1128/jvi.00127-20 (2020).

5. Fan Y, Zhao K, Shi ZL, Zhou P. Bat Coronaviruses in China. Viruses. 2019;11:210.

6. Zhou P, Yang XL, Wang XG, Hu B, Zhang L, Zhang W, Si HR, Zhu Y, Li B, Huang CL, Chen HD. A pneumonia outbreak associated with a new coronavirus of probable bat origin. Nature. 2020;579:270-3. https://doi.org/10.1038/s41586020-2012-7 (2020)

7. To KK, Tsang OT, Yip CC, Chan KH, Wu TC, Chan JM, Leung WS, Chik TS, Choi CY, Kandamby DH, Lung DC. Consistent detection of 2019 novel coronavirus in saliva. Clinical infectious diseases: an official publication of the Infectious Diseases Society of America. 2020. https://doi.org/10.1093/ cid/ciaa149 (2020).

8. Falsey AR, Walsh EE. Novel coronavirus and severe acute respiratory syndrome. Lancet (London, England). 2003;361:1312.

9. The Lancet. MERS-CoV: a global challenge. Lancet 381, 1960 (2013).

10. Zhu N, Zhang D, Wang W, Li X, Yang B, Song J, Zhao X, Huang B, Shi W, Lu R, Niu P. A novel coronavirus from patients with pneumonia in China, 2019. New England Journal of Medicine. 2020. https://doi.org/10.1056/NEJMoa2001017 (2020).

11. Li Q, Guan X, Wu P, Wang X, Zhou L, Tong Y, Ren R, Leung KS, Lau EH, Wong JY, Xing X. Early transmission dynamics in Wuhan, China, of novel coronavirus-infected pneumonia. New England Journal of Medicine. 2020.

12. Eurosurveillance Editorial Team. Note from the editors: World Health Organization declares novel coronavirus (2019-nCoV) sixth public health emergency of international concern. Eurosurveillance. 2020;25.

13. WorldHealth Organization. Infection prevention and control during health care when novel coronavirus ( $(n \mathrm{CoV}) "$ infection is suspected: interim guidance, January 2020. World Health Organization; 2020. Available: https://www.who.int/publicationsdetail/infectionpreventio and-control-duringhealth-care-when-novel-coronavirus-(ncov)infection-issuspected- 20200125.

14. Backer JA, Klinkenberg D, Wallinga J. Incubation period of 2019 novel coronavirus (2019-nCoV) infections among travellers from Wuhan, China, 20-28 January 2020. Eurosurveillance. 2020;25.

15. The American Dental Association (ADA). Coronavirus Frequently Asked Questions. 2020 [updated March 16, 2020]; Available from: https:// success.ada.org/en/practice-management/patients/ coronavirus-frequently-asked-questions.

16. Centers for Disease Control and Prevention (CDC). CDC Developing Guidance Regarding Responding to COVID-19 in Dental Settings. Division of Oral Health, National Center for Chronic Disease Prevention and Health Promotion; 2020 [updated March 11 2020]; Available from: https://www.cdc. gov/oralhealth/infectioncontrol/statement-COVID. html.

17. Centers for disease control and prevention. Update and interim guidelines on outbreak of 2019 Novel coronavirus (2019-nCoV):2020 https://emergency. 
cdc.gov/han/han00427.asp. (Accessed on 5 April 5, 2020).

18. Khader, Y., Al Nsour, M., Al-Batayneh, O. B., Saadeh, R., Bashier, H., Alfaqih, M., AlShurman, B. A., Dentists' awareness, perception, and attitude regarding COVID-19 and infection control: A crosssectional study among Jordanian dentists.JMIR, 2020 https://preprints.jmir.org/preprint/19047

19. Imai T, Takahashi K, Hasegawa N, Lim MK, Koh D: SARS risk perceptions in healthcare workers, Japan. Emerg Infect Dis 2005, 11:404-410.

20. Quah SR, Hin-Peng L. Crisis prevention and management during SARS outbreak, Singapore. Emerging Infectious Diseases. 2004;10(2):364-68.

21. Khan MU, Shah S, Ahmad A, Fatokun O. Knowledge and attitude of healthcare workers about middle east respiratory syndrome in multispecialty hospitals of Qassim, Saudi Arabia. BMC Public Health. 2014;14:1281. http://www.biomedcentral. com/1471-2458/14/1281

22. Carr CT, Hayes RA. Social media: Defining, developing, and divining. Atlantic journal of communication. 2015;23:46-65.

23. Shimizu K. 2019-nCoV, fake news, and racism. The Lancet. 2020;395:685-6.

24. Thomas Z. Misinformation on coronavirus causing. BBC.2020 'infodemic'.https://www.bbc.com/ news/technology-51497800 (Accessed 09 March 2020)

25. Meng L, Hua F, Bian Z. Coronavirus disease 2019 (COVID-19): emerging and future challenges for dental and oral medicine. Journal of Dental Research. 2020 Mar .12:22034520914246. doi: 10.1177/0022034520914246

26. Abolfotouh MA, AlQarni AA, Al-Ghamdi SM, Salam M, Al-Assiri MH, Balkhy HH. An assessment of the level of concern among hospital-based health-care workers regarding MERS outbreaks in Saudi Arabia. BMC infectious diseases. 2017;17:4. PMID: 28049440. doi: 10.1186/s12879- 016-20968.

27. Baseer MA, Ansari SH, AlShamrani SS, Alakras AR, Mahrous R, Alenazi AM. Awareness of droplet and airborne isolation precautions among dental health professionals during the outbreak of corona virus infection in Riyadh city, Saudi Arabia. Journal of clinical and experimental dentistry. 2016;8:e379- e87. PMID: 27703605. doi: 10.4317/ jced.52811.

28. Zemouri C, de Soet H, Crielaard W, Laheij A. A scoping review on bio-aerosols in healthcare and the dental environment. PloS one. 2017;12. PMID: 28531183. doi: 10.1371/journal.pone.0178007

29. Bener A, Al-Khal A. Knowledge, attitude and practice towards SARS. The journal of the Royal Society for the Promotion of Health. 2004;124:16770.

30. JoukarF, Mansour-Ghanaei F, Soati F, Meskinkhoda P. Knowledge levels and attitudes of health care professionals toward patients with hepatitis C infection. World Journal of Gastroenterology: WJG. 2012;18(18):2238-2244.

31. Richmond JA, Dunning TL, Desmond PV. Health professionals' attitudes toward caring for people with hepatitis C. Journal of viral hepatitis. 2007;14(9):624-32.

32. Thu TA, Anh NQ, Chau NQ, Hung NV: Knowledge, attitude and practices regarding standard and isolation precautions among Vietnamese health care workers: a multicenter cross-sectional survey. Intern Med 2012, 2:115.

33. Arefi P, Cardoso E, Azarpazhooh A. Reexamining dental outreach programs: A model for local empowerment and sustainable development. The Journal of the American Dental Association. 2020. S0002-8177(20)30040-4. doi: 10.1016/j. adaj.2020.01.023.

34. Akpodiete A, Isara AR. Concerns about the knowledge of multi drug resistant tuberculosis among health care workers and patients in southern Nigeria. Am J Respir Crit Care Med.2014, 189,A3215.

35. Tam DK, Lee S, Lee SS. Impact of SARS on avian influenza preparedness in healthcare workers. Infection. 2007;35:320-25.

36. Fisher WA, Fisher JD, Rye BJ. Understanding and promoting AIDS-preventive behavior: insights from the theory of reasoned action. Health Psychology. 1995;14:255-64. 